\title{
PHARMACOKINETICS AND BIOAVAILABILITY OF ORTHOSIPHON STAMINEUS ETHANOLIC EXTRACT AND ITS-NANO LIPOSOMES IN SPRAGUE-DAWLEY RATS
}

\author{
ARMAGHAN SHAFAEI ${ }^{1}$, MOHAMMED ALI AHMED SAEED ${ }^{1}$, ABDALRAHIM F. A. AISHA ${ }^{1}$, ZHARI ISMAIL ${ }^{*}$ \\ 1Department of Pharmaceutical Chemistry, School of Pharmaceutical Sciences, Universiti Sains Malaysia, Minden, Penang 11800, Malaysia \\ Email: ismailzhari@gmail.com
}

Received: 01 Oct 2016 Revised and Accepted: 11 Nov 2016

\section{ABSTRACT}

Objective: This study aimed to perform pharmacokinetic profile of rosmarinic acid (RA), sinensitin (SIN), eupatorin (EUP) and 3'-hydroxy-5,6,7,4'tetramethoxyflavone (TMF) in Orthosiphon stamineus ethanolic extract (OS-E) and its nanoliposomes (OS-EL) after oral and intravenous administration in Sprague-Dawley rat's plasma by developing and validating a high-performance liquid chromatography (HPLC) method with ultraviolet (UV) detection.

Methods: An isocratic elution program consisting of methanol: tetrahydrofuran: water $\left(0.1 \% \mathrm{H}_{3} \mathrm{PO}_{4}\right)$ mixture in the volume ratio 55 : 5 : 40 on Nucleosil C18 column $(250 \times 4.6 \mathrm{~mm}$ internal diameter $\times 5 \mu \mathrm{m}$ particles size $)$ was applied. The current study followed a two-ways crossover study design. OS-E and OS-EL were administered orally at 1000 and $500 \mathrm{mg} / \mathrm{kg}$, respectively. They were also administered intravenously at $250 \mathrm{mg} / \mathrm{kg}$ via the tail vein.

Results: The HPLC-UV method was successfully developed and validated for simultaneous determination of major chemical constituent from OS-E and OS-EL in rat's plasma. The method recorded the mean recoveries from extraction were between 91.39 and $100.32 \%$. With regards to the intravenous administration of OS-EL, all four marker compounds appeared to be poorly distributed and cleared slowly from the body compared to OS-E. Whilst in oral administration of OS-EL, the bioavailability of all marker compounds were higher than OS-E due to higher solubility of encapsulation in phospholipids.

Conclusion: The higher solubility and bioavailability of OS-EL may contribute to encapsulation in phospholipids.

Keywords: Rosmarinic acid, Sinensitin, Eupatorin, 3'-hydroxy-5,6,7,4'-tetramethoxyflavone, HPLC-UV, Pharmacokinetic, Bioavailability

(c) 2017 The Authors. Published by Innovare Academic Sciences Pvt Ltd. This is an open access article under the CC BY license (http://creativecommons.org/licenses/by/4. 0/] DOI: http://dx.doi.org/10.22159/ijpps.2017v9i1.12407

\section{INTRODUCTION}

Orthosiphon stamineus (OS) Benth. (Lamiaceae) is a medicinal plant grown in Southeast Asia and currently cultivated in Indonesia and Malaysia. The local name of OS in Malaysia is Misai Kucing. The leaves of OS have been used traditionally in treating angiogenesisrelated diseases, urinary lithiasis, edema, inflammation, eruptive fever, influenza, hepatitis, jaundice, rheumatism, diabetes, and hypertension [1]. OS leaves are used commonly in South-east Asian and European countries as herbal tea, known as "Java tea". Various chemical constituents including flavonoids, terpenoids, saponins, hexoses, organic acids, chromene, myo-inositol, and polyphenols have been identified in OS leaves [2]. The major caffeic acid derivatives present in OS is RA (fig. 1A) and 3 main flavonoids (lipophilic flavones) including TMF, SIN and EUP (fig. 1B-D). Numerous studies have reported that lipophilic flavones of OS possess potential therapeutic properties such as cytotoxic effect, diuretic, and uricosuric actions in rats [2-3]. Therefore, these compounds have been given considerable attention as markers of pharmacological activity by several researchers [4-6]. However, lipophilic compounds (TMF, SIN and EUP) suffer from poor aqueous solubility which limits os oral bioavailability and therapeutic applications. Therefore, improving solubility of lipophilic flavones may improve bioavailability and hence the overall pharmacological activity of OS extracts. Liposomal drug delivery systems have been developed for improving solubility, bioavailability and efficacy, reduced toxicity, and increased product stability of herbal extracts [7].
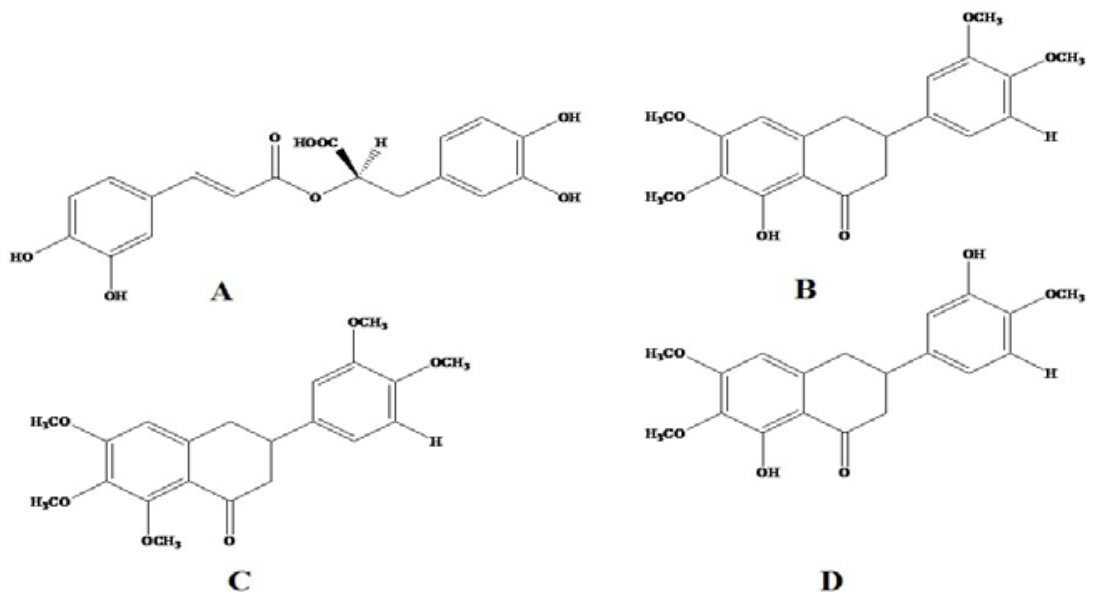

Fig. 1: Chemical structure of (A) rosmarinic acid (B) 3 '-hydroxy-5,6,7,4'-tetramethoxyflavone, (C) sinensetin, and (D) eupatorin 
It is believed that drug absorption is a key component of drug bioavailability that determines drug's efficacy [8]. In the lead optimisation phases of drug discovery, the pharmacokinetics of the absorbed components in blood is the key to design in vivo efficacy studies [9]. Thus, screening active constituents contained of herbs in blood is a great challenge and major obstacle for further pharmacological investigation. It is clear that those compounds which can be absorbed into the blood have the chance to show bioactivities. If they remain for a very short time in the body without maintaining an effective blood concentration, that will not be a material basis for efficacy [8-11].

Quantitative analyses for in vivo pharmacokinetic application have been documented using either high-performance liquid chromatography (HPLC-UV), high-performance liquid chromategraphy-tandem mass spectrometry (HPLC-MS/MS), or ultraperformance liquid chromatography/mass spectrometry (UPLC-QTOF) [8-11]. To the best of our knowledge, multiple component levels that can be reached in plasma are very low. Therefore, developing a specific and sensitive method for identification and quantification of the active constituent of herbs in plasma is required.

Several HPLC methods for analysis of the active constituent of OS including RA, TMF, SIN and EUP have been reported in the literature [2, 12-13]. However, they were mainly developed to analyse the compounds in plant extracts but not in plasma. Moreover, the sensitivity of these methods, reported to be approximately $1000 \mathrm{ng} / \mathrm{ml}[2,5,13]$, might not be sufficient for their pharmacokinetic studies. Up to now, there is no report on pharmacokinetic properties of multiple absorbed components from OS-E and its nano formulation prepared by liposomes from soybean phospholipids (OS-EL) in the relevant literature. This information is crucial and vital to explore novel drug candidates further. Therefore, the aim of this study is to perform pharmacokinetic profile of multiple absorbed components such as RA, SIN, EUP, and TMF in OS-E and OS-EL after oral and intravenous administration in Sprague-Dawley rat plasma by developing and validating an HPLC method with UV detection.

\section{MATERIALS AND METHODS}

\section{Materials}

Standardised OS-E (containing 33.95, 2.37, 5.44 and $2.64 \mathrm{mg} / \mathrm{g}$ of RA, TMF, SIN and EUP, respectively) and its nanoliposomes (OS-EL) were obtained from Department of Pharmaceutical Chemistry, School of Pharmaceutical Sciences, Universiti Sains Malaysia (USM). Preparation of standardised OS-E and OS-EL are briefly described here. The OS leaves were purchased from a specialised supplier of herbal products in Malaysia (Herbagus Trading, Kepala Batas, Pulau Pinang) and identified at the herbarium of School of Biological Sciences Universiti Sains Malaysia, where a voucher sample was deposited (reference number: 11009). The leaves were pulverized into a fine powder using milling machine (Retsch $\mathrm{GmbH}$, Germany), and saved in air-tight plastic bags until used. In preparing the extract, $100 \mathrm{~g}$ plant powder was added to $500 \mathrm{ml}$ ethanol and mixed continuously on a magnetic stirrer for $48 \mathrm{~h}$ at $50{ }^{\circ} \mathrm{C}$. After cooling, extracts were filtered using Whatman filter paper No.1 (Whatman, England), concentrated at $50{ }^{\circ} \mathrm{C}$ under vacuum using a rotary evaporator (RE121 Buchi, Switzerland), and dried using a freezedrying system (Labconco, USA). The content of RA, TMF, SIN, and EUP in OS-E was measured using HPLC method as described by Siddiqui and Zhari [6].

Liposomes of OS-E extract (OS-EL) were prepared using the film method as the following; soybean phospholipids was dissolved in chloroform and OS-E extract was dissolved in methanol, the solutions were mixed, and the solvent was evaporated under vacuum using rotary evaporator at $45^{\circ} \mathrm{C}$ for $30 \mathrm{~min}$, followed by drying in oven at $60^{\circ} \mathrm{C}$ for $1 \mathrm{~h} \mathrm{[7].}$

\section{Characterization of OS-EL}

OS-EL was characterised for solubility, entrapment efficiency, Fourier transform infrared spectroscopy (FTIR), Transmission Electron Microscopy (TEM), and particle size and zeta potential [7].

\section{Chemicals}

RA, SIN, EUP and TMF standard compounds (purity $\geq 98 \%$ ) were purchased from Indofine (New Jersey, USA). HPLC grade methanol and phosphoric acid were purchased from Merck (Petaling Jaya, Selangor, Malaysia). Deionized water for HPLC was prepared using Ultra-pure water purifier system (Elgastat, Bucks, UK). Heparin was obtained from Sigma (Petaling Jaya, Selangor, Malaysia).

\section{Instrumentation}

The HPLC was performed using an Agilent Technologies series 1260 infinity (Waldronn, Germany) system equipped with a quaternary pump (G 1311 C), autosampler (G 1329 B), column oven (G 1316A) and ultraviolet (UV) detector (G 1314 F).

\section{Plasma sample extraction}

In a $1.5 \mathrm{ml}$ microcentrifuge tube, an aliquot of $200 \mu \mathrm{l}$ plasma was added and mixed with $200 \mu \mathrm{l}$ HPLC grade methanol. The mixture was vortexed for 2 min then centrifuged at $8000 \mathrm{rpm}$ for $10 \mathrm{~min}$. The supernatant was transferred into a $0.15 \mathrm{ml}$ glass conical insert. For analysis, $20 \mu \mathrm{l}$ of supernatant was injected into the HPLC system.

\section{Development and validation of HPLC method}

\section{Chromatographic condition}

The HPLC analysis was performed according to the method described by Siddiqui and Zhari [6]. The chromatographic analysis was carried out on a Nucleosil C18 column $(250 \times 4.6 \mathrm{~mm}$ internal diameter $\times 5 \mu \mathrm{m}$ particles size) (Macherey Nagel, Germany). The column temperature was maintained at $25{ }^{\circ} \mathrm{C}$ and the injection sample $(20 \mu \mathrm{l})$ was eluted with an isocratic mobile phase comprising methanol: tetrahydrofuran: water $\left(0.1 \% \mathrm{H}_{3} \mathrm{PO}_{4}\right)$ mixture in the volume ratio 55: 5: 40. Flow rate was $0.7 \mathrm{ml} / \mathrm{min}$ and detection was carried out at $330 \mathrm{~nm}$.

\section{Calibration curves, linearity ranges, limit of detection (LOD) and limit of quantification (LOQ)}

The calibration curves were constructed using six concentrations of the standard compounds (RA, TMF, SIN and EUP) in blank rat plasma samples at $0.3125,0.625,1.25,2.5,5$ and $10 \mu \mathrm{g} / \mathrm{ml}$. The calibration curves were constructed by plotting peak area against concentrations of each standard compound. The calibration curves were analysed using linear regression analysis.

LOD and LOQ were determined by injecting successive two-fold dilution of the stock solutions in blank rat plasma. The LOD was defined as the lowest concentration that the analytical system can reliably differentiate from the background level. However, the LOQ was defined as the lowest quantifiable concentration that can be measured by a standard level of confidence [14].

\section{Within-day and between-day precisions and recovery of plasma extraction}

The within-day precisions were determined at six concentrations with six replicates each carried out on a single day, whereas the between-day values were obtained over six consecutive days. The recovery of standard compounds from plasma was determined by comparing the responses obtained after liquid-liquid extraction of standard compounds from spiked plasma with those obtained after the direct injection of standard compounds prepared in methanol. The percentage recovery was calculated using the following equation:

$\%$ Recovery $=[$ calculated concentration/theoretical concentration $] \times 100$ The above analysis was carried out in triplicates.

\section{Animals}

Male Sprague-Dawley rats weighing 350-410 g were obtained from the Animal Research and Service Centre (ARASC), Universiti Sains Malaysia, Penang, Malaysia. The animals were maintained on a $12 \mathrm{~h}$ light-dark cycle, at room temperature and were allowed free access to standard food pellets. 


\section{Ethical approval}

The study was approved by the Animal Ethics Committee of Universiti Sains Malaysia, Penang, Malaysia [Protocol No: USM/ Animal Ethics Approval/2014/(598)].

\section{Pharmacokinetic study of OS-E and OS-EL}

The study was conducted based on a two-ways crossover study design [10]. The animals were fasted overnight with free access to water prior to the experimentation. The food was only allowed after the sampling of blood at $4 \mathrm{~h}$. In the first occasion, 3 rats (group I) were randomised to receive $250 \mathrm{mg} / \mathrm{kg}$ of $\mathrm{OS}-\mathrm{E}$, administered intravenously (IV) via the tail vein. Three rats (group II) received $1000 \mathrm{mg} / \mathrm{kg}$ of the same extract orally, and three rats (group III) were randomised to receive $250 \mathrm{mg} / \mathrm{kg}$ of OS-EL, administered intravenously via the tail vein. Three rats (group IV) received 500 $\mathrm{mg} / \mathrm{kg}$ of OS-EL orally.

After a washout period of $2 \mathrm{w}$, the animals from group (I) were given $1000 \mathrm{mg} / \mathrm{kg}$ of OS-E orally, whilst those from group (II) received 250 $\mathrm{mg} / \mathrm{kg}$ intravenously of OS-E, and the animals from group (III) were given $500 \mathrm{mg} / \mathrm{kg}$ OS-EL orally, whilst those from group (IV) received $250 \mathrm{mg} / \mathrm{kg}$ intravenously of OS-EL. The rats were placed in animal restraining cages during blood collection. Blood samples of $0.4 \mathrm{ml}$ were withdrawn from the tail vein at $0,0.5,1,1.5,2,2.5,3,3.5,4,12$ and $24 \mathrm{~h}$ after IV injection or at $0,1.5,2,2.5,3,3.5,4,4.5,5,6,8,12$ and $24 \mathrm{~h}$ after oral administration. The blood samples were collected into microcentrifuge tubes containing $20 \mu \mathrm{l}$ of heparin solution. All blood samples were centrifuged at $3000 \mathrm{rpm}$ for $10 \mathrm{~min}$. The resulting plasma samples were kept at $-20^{\circ} \mathrm{C}$ prior to HPLC analysis.

\section{Determination of pharmacokinetic parameters}

The following pharmacokinetic parameters were estimated from the data of IV administration: area under plasma concentration-time curve $\left(\mathrm{AUC}_{0 \rightarrow \infty}\right)$, elimination rate constant $\left(K_{\mathrm{e}}\right)$, biological half-life $\left(t_{1 / 2}\right)$, the volume of distribution $\left(V_{\mathrm{d}}\right)$, and clearance $(C L)$. The value of $\mathrm{AUC}_{0 \rightarrow \infty}(\mu \mathrm{g} \mathrm{h} / \mathrm{ml})$ was determined by adding the area from time zero to the last sampling time $\left(\mathrm{AUC}_{0 \rightarrow \mathrm{t}}\right)$ to the area from last sampling time to infinity $\left(\mathrm{AUC}_{\mathrm{t} \rightarrow \infty}\right)$. The $K \mathrm{Ke}\left(\mathrm{h}^{-1}\right)$ was calculated using the relationship, $t_{1 / 2}=\ln 2 / K$ e while $V_{\mathrm{d}}(\mathrm{l} / \mathrm{kg})$ was calculated from the relationship, $V_{\mathrm{d}}=$ dose $/ K \mathrm{e} \times \mathrm{AUC}_{0 \rightarrow \infty}$. Clearance $C L(\mathrm{l} / \mathrm{kg} \mathrm{h})$ was calculated from the relationship, $C L=\operatorname{dose} / \mathrm{AUC}_{0 \rightarrow \infty}$. However, the area under plasma concentration-time curve $\operatorname{AUC}_{0 \rightarrow 24}(\mu \mathrm{g} \mathrm{h} / \mathrm{ml})$, maximum concentration $\left(C_{\max }\right)$ and time to reach $T_{\max }$ to maximum concentration were calculated from the data of oral administration. The percentage of the absolute bioavailability of the standard compounds was estimated from the following equation [10].

$$
\% \text { Absolute bioavailability (F) = (AUC for oral/AUC for IV) a }
$$$$
\times(\text { IV dose/oral dose }) \times 100
$$

\section{Statistical analysis}

The samples were analysed in triplicates and results were presented as mean \pm SEM, $\mathrm{n}=6$. The difference between pharmacokinetic parameters after oral and IV administration of OS-E and OS-EL was compared by a two-sided t-test using the Statistical Package for Social Sciences (SPSS, version 18.0).

\section{RESULTS}

\section{Characterization of OS-EL}

OS-EL showed substantial enhancement of extract's solubility from $956 \pm 34$ to $3979 \pm 139 \mu \mathrm{g} / \mathrm{ml}$, with entrapment efficiency of $66.2 \pm 0.9 \%$. FTIR study indicates an interaction between soybean phospholipids (SPL) and OS-E extract (fig. 2). Remarkable changes were observed in the infrared absorption spectra as a result of incorporation of OS-E extract in phospholipids; the broad band corresponding to $\mathrm{OH}$ groups was shifted from $3387 \mathrm{~cm}^{-1}$ to 3421 $\mathrm{cm}^{-1}$, the $\mathrm{C}=0$ bonds at $1695 \mathrm{~cm}^{-1}$ and $1607 \mathrm{~cm}^{-1}$ disappeared, the band corresponding to $\mathrm{C}=\mathrm{O}$ stretching in phospholipids was shifted from $1650 \mathrm{~cm}^{-1}$ to $1634 \mathrm{~cm}^{-1}$, the band at $1267 \mathrm{~cm}^{-1}$ was shifted to lower frequency $\left(1225 \mathrm{~cm}^{-1}\right)$ with much lower oscillation strength, the band at $1232 \mathrm{~cm}^{-1}$ disappeared, and band at $1075 \mathrm{~cm}^{-1}$ was shifted to $1071 \mathrm{~cm}^{-1}$. The most pronounced spectral changes can be observed in the spectral region corresponding to the polar heads of phospholipids. Such changes may represent hydrogen bonding between the polar heads of phospholipids with the hydroxyl groups in OS-E extract. Hydrogen bonding can also occur between the keto groups of flavonoids and oxygen groups of phospholipids. The hydrophobic interaction may also occur between the flavone's methoxy groups and the phospholipid tails. TEM and dynamic light scattering show the presence of round anionic nanoliposomes with particle size and zeta potential of $152.5 \pm 1.1 \mathrm{~nm}$ and-49.8 $\pm 1.0 \mathrm{mV}$, respectively [7] (fig. 3).
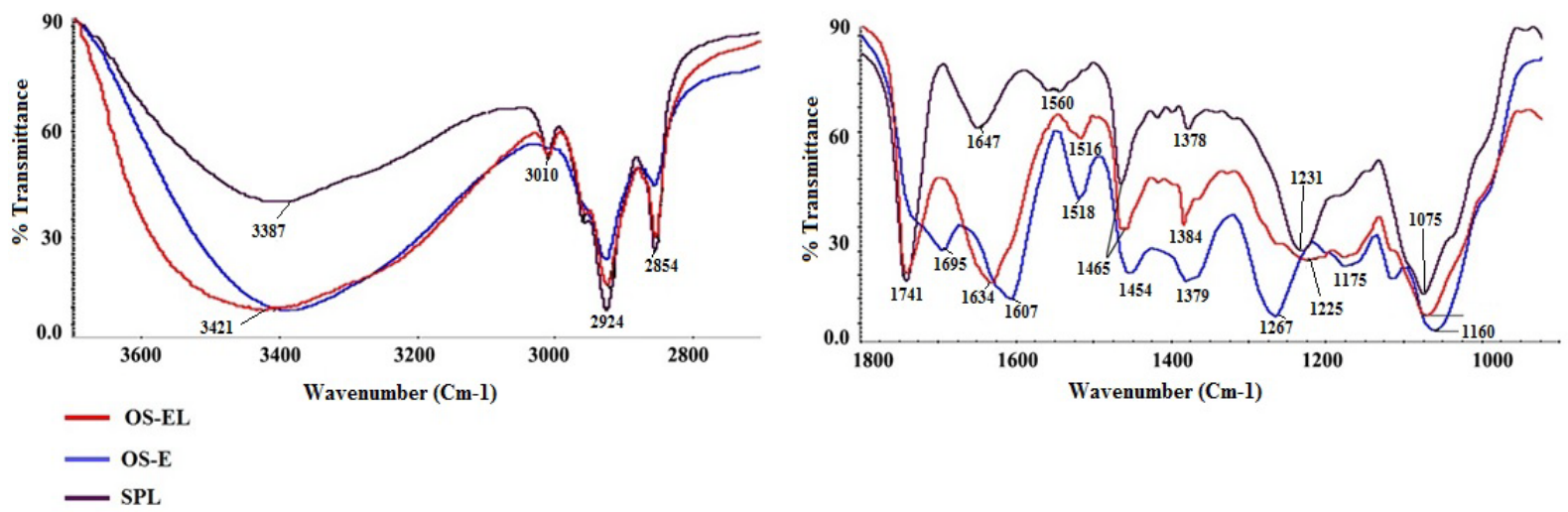

Fig. 2: FTIR spectra of OS-E, SPL and OS-EL [7]

\section{Development and validation of HPLC method}

The present HPLC method was developed and validated for application in the pharmacokinetic study. RA, TMF, SIN and EUP were well-separated from potential interfering compounds in the plasma under the described chromatographic condition. Chromatographic peaks were identified with the aid of pure standards of RA, TMF, SIN, and EUP based on retention time. The chromatograms of blank rat plasma, plasma spiked with mixed standards of RA, TMF, SIN and EUP, and plasma samples after oral and IV administration of OS-E and OS-EL are illustrated in fig. 4. The total run time was $30 \mathrm{~min}$. The linearity of detector response was assessed for extracted plasma samples.

Calibration curve of standard compounds are presented in fig. 5 . In OS-E and OS-EL, the elution profile of standard compounds in plasma is similar to that observed in the corresponding standards. 
A

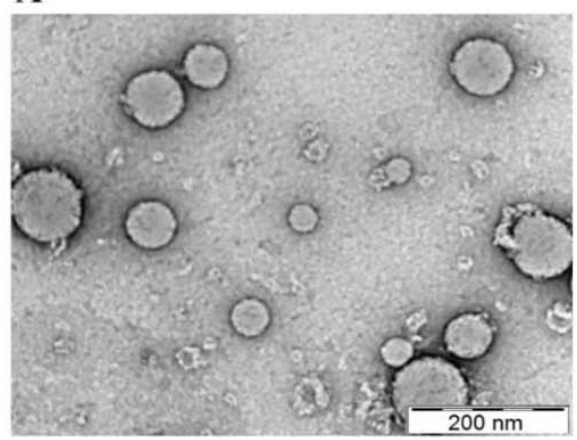

C

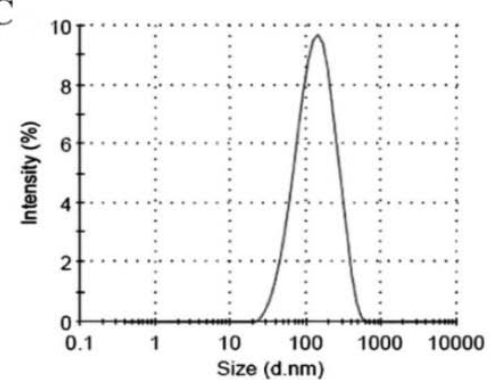

B

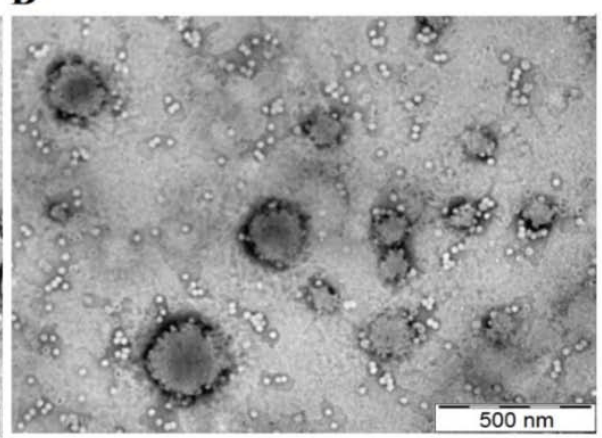

D

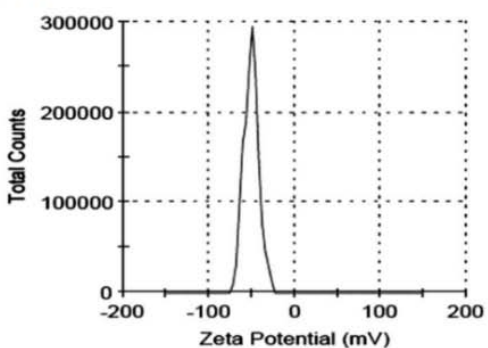

Fig. 3: Morphology and particle size analysis of the OS-EL. Transmission Electron Microscopy (TEM) photograph of OS-EL (A) and their lipid bilayer (B), particle size distribution (C), and zeta potential distribution (D). This fig. confirms the presence of round liposomes with narrow size distribution $(<200 \mathrm{~nm})$ and a negative surface charge [7]

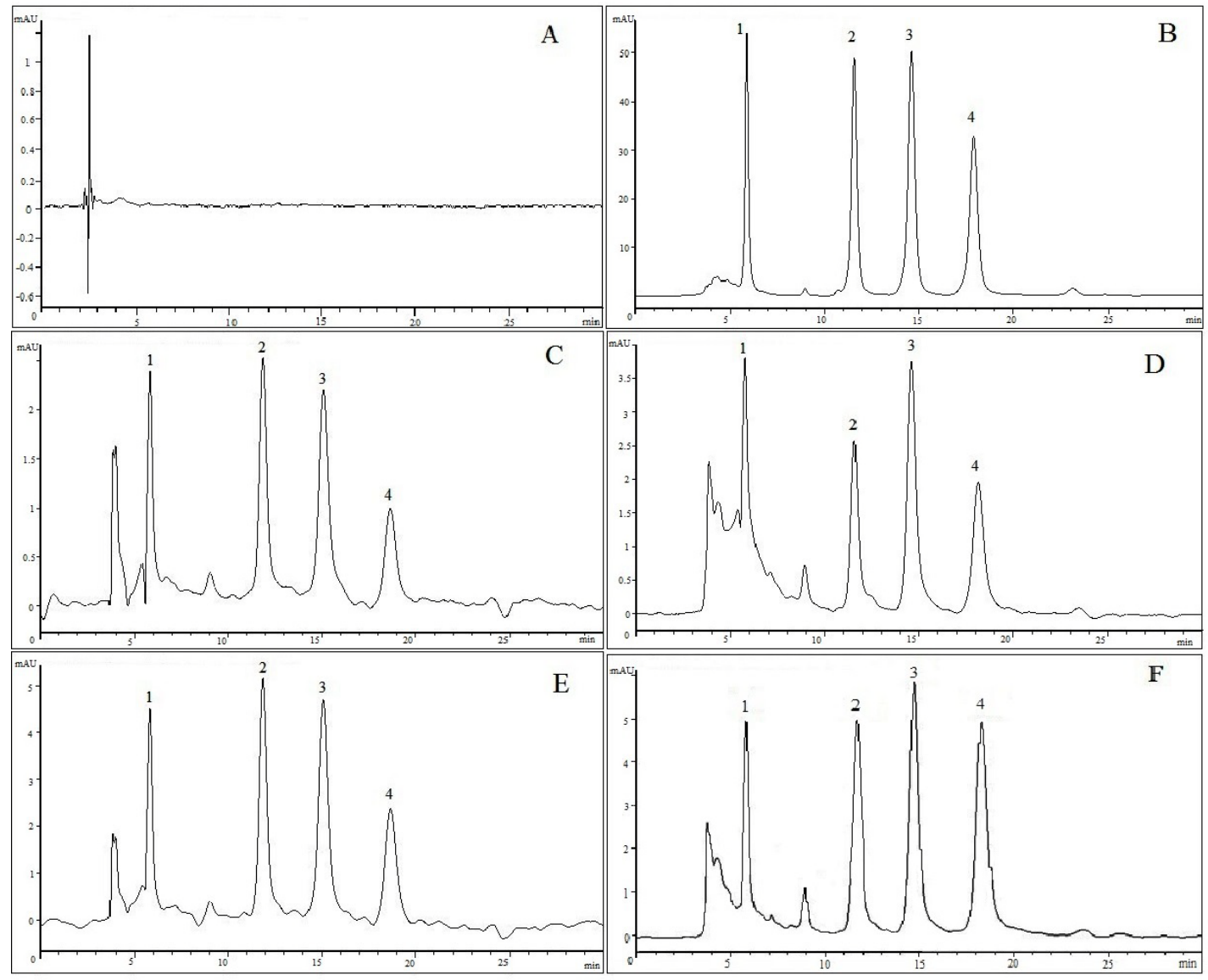

Fig. 4: Chromatograms from the analysis of RA (1), TMF (2), SIN (3) and EUP (4). (A) blank rat plasma; (B) rat plasma spiked with 10 $\mu \mathrm{g} / \mathrm{ml}$ of 1, 2, 3 and 4, respectively; (C) rat plasma at $1 \mathrm{~h}$ after intravenous administration of $250 \mathrm{mg} / \mathrm{kg} 0 S$-E; (D) rat plasma at $4 \mathrm{~h}$ after oral administration of $1000 \mathrm{mg} / \mathrm{kg}$ OS-E; (E) rat plasma at $1 \mathrm{~h}$ after intravenous administration of $250 \mathrm{mg} / \mathrm{kg}$ OS-EL; (F) rat plasma at $4 \mathrm{~h}$ after oral administration of $500 \mathrm{mg} / \mathrm{kg} \mathrm{OS}$-EL 


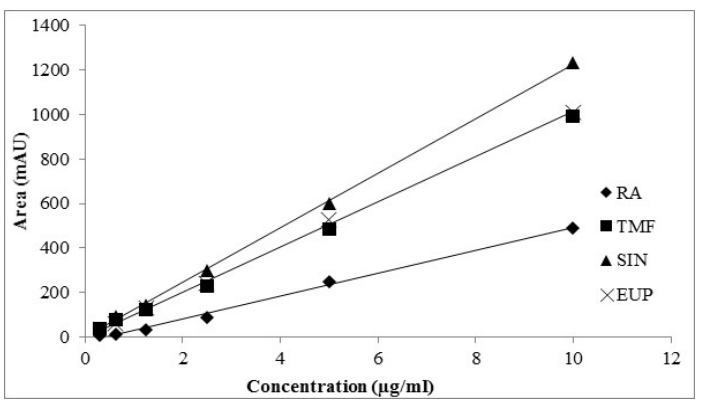

Fig. 5: Mean standard calibration curves of RA, TMF, SIN and EUP prepared using blank rat plasma

Linearity was evaluated by determining a series of six concentrations of the standard solution in three replicates. Linear regression equations and correlation coefficients were established from the graph by plotting the mean of peak area versus the concentration. The standard solutions of the standard compounds showed good linearity over the evaluated concentration in the range of $0.3125-10 \mu \mathrm{g} / \mathrm{ml}$. In addition, the correlation coefficient values $\left(\mathrm{R}^{2}\right)$ of all four marker compounds were greater than 0.999 . The sensitivity of the method was evaluated by LOD and LOQ analyses (table 1).

Deproteinization with methanol gave a high percentage recovery ranged from $91.39 \%$ to $100.32 \%$, with \%RSD $1.04-7.85$ which indicates the good accuracy of the method (table 2). Thus, implying deproteinization of the plasma with methanol did not result in any substantial loss of the chemical constituents. The peak area was applied to calculate the \%RSD of the standard compounds. Withinday and between-day precision data are shown in table 2 . Acceptable precision was achieved with the method as the mean $\%$ RSD for all standard compounds is less than $6 \%$. The validated results indicate that the method is reliable, repeatable, and reproducible.

Table 1: Calibration data, LOD and LOQ of the reported HPLC method

\begin{tabular}{|c|c|c|c|c|c|}
\hline Compound & LOD $(\mu \mathrm{g} / \mathrm{ml})$ & $\mathrm{LOQ}(\mu \mathrm{g} / \mathrm{ml})$ & Linearity range $(\mu \mathrm{g} / \mathrm{ml})$ & Equation & $\mathbf{R}^{2}$ Value \\
\hline $\mathrm{RA}$ & 0.11 & 0.29 & $0.3125-10$ & $Y=27.35 X-7.782$ & 0.999 \\
\hline TMF & 0.13 & 0.41 & $0.3125-10$ & $Y=37.89 X+34.49$ & 0.999 \\
\hline SIN & 0.11 & 0.36 & $0.3125-10$ & $Y=49.28 X+43.49$ & 0.999 \\
\hline EUP & 0.13 & 0.42 & $0.3125-10$ & $Y=42.62 X+10.29$ & 0.999 \\
\hline
\end{tabular}

Table 2: Extraction recovery, within-day and between-day precision and accuracy values $(n=6)$ for RA, TMF, SIN and EUP

\begin{tabular}{|c|c|c|c|c|c|c|c|}
\hline Name & Concentration & Recovery & & Within Day & & Between day & \\
\hline & $(\mu \mathrm{g} / \mathrm{ml})$ & Mean & RSD (\%) & Accuracy (\% of true value) & RSD (\%) & Accuracy (\% of true value) & RSD (\%) \\
\hline \multirow[t]{6}{*}{$\mathbf{R A}$} & 0.3125 & 98.23 & 1.36 & 98.14 & 0.33 & 98.56 & 1.42 \\
\hline & 0.625 & 95.34 & 1.22 & 97.83 & 2.07 & 100.17 & 5.31 \\
\hline & 1.25 & 91.39 & 6.97 & 97.54 & 2.76 & 101.01 & 3.59 \\
\hline & 2.5 & 99.98 & 6.82 & 101.08 & 1.47 & 94.61 & 1.17 \\
\hline & 5 & 96.67 & 1.64 & 101.23 & 5.06 & 101.93 & 0.96 \\
\hline & 10 & 97.89 & 3.39 & 100.40 & 2.09 & 95.50 & 2.80 \\
\hline \multirow[t]{6}{*}{ TMF } & 0.3125 & 98.56 & 2.31 & 100.43 & 0.05 & 100.33 & 3.29 \\
\hline & 0.625 & 93.35 & 3.13 & 98.31 & 2.65 & 96.30 & 2.52 \\
\hline & 1.25 & 95.22 & 5.45 & 97.61 & 1.33 & 96.94 & 1.41 \\
\hline & 2.5 & 99.12 & 4.06 & 102.93 & 0.91 & 102.65 & 3.40 \\
\hline & 5 & 98.10 & 3.51 & 96.25 & 3.15 & 104.56 & 2.32 \\
\hline & 10 & 98.90 & 1.04 & 97.45 & 0.44 & 102.51 & 3.34 \\
\hline \multirow[t]{6}{*}{ SIN } & 0.3125 & 92.04 & 4.03 & 99.20 & 1.58 & 98.72 & 2.79 \\
\hline & 0.625 & 92.60 & 7.85 & 93.54 & 2.97 & 98.56 & 2.70 \\
\hline & 1.25 & 93.03 & 3.78 & 97.24 & 1.48 & 102.67 & 1.49 \\
\hline & 2.5 & 93.52 & 6.09 & 103.63 & 2.51 & 101.11 & 0.78 \\
\hline & 5 & 94.75 & 2.02 & 97.04 & 0.03 & 100.30 & 4.90 \\
\hline & 10 & 93.27 & 5.96 & 99.67 & 0.33 & 99.35 & 1.94 \\
\hline \multirow[t]{6}{*}{ EUP } & 0.3125 & 93.11 & 4.71 & 100.07 & 1.89 & 98.86 & 1.70 \\
\hline & 0.625 & 97.10 & 6.13 & 99.78 & 3.09 & 99.22 & 2.61 \\
\hline & 1.25 & 91.39 & 6.74 & 104.51 & 1.63 & 102.62 & 0.95 \\
\hline & 2.5 & 99.56 & 4.64 & 100.00 & 1.54 & 100.89 & 1.17 \\
\hline & 5 & 93.46 & 4.93 & 99.05 & 0.05 & 98.97 & 0.05 \\
\hline & 10 & 91.50 & 1.59 & 98.74 & 0.79 & 102.07 & 1.85 \\
\hline
\end{tabular}

Determination and quantification of RA, TMF, SIN and EUP content in rat's Plasma

The HPLC method was applied for analyses of RA, TMF, SIN and EUP in rat's plasma after oral and IV administration of OS-E and OS-EL. As shown in fig. 4 selected standard compounds were well separated by the developed HPLC method. The course of mean plasma concentration versus time profiles of RA, TMF, SIN, and EUP after IV and oral administration of OS-E and OS-EL are shown in fig. 6-7. Results were derived from the mean of a peak area from three replicate injections.

\section{Pharmacokinetic study of OS-E and OS-EL}

Following intravenous administration of OS-E and OS-EL showed a gradual decline in its plasma concentrations (fig. 6-7). The estimated volume of distribution $\left(V_{d}\right)$ of the marker compounds in OS-E was relatively higher than OS-EL. This suggests that the marker compounds were more distributed into the tissue compartment in OS-E compared to OS-EL (table 3).

However, these marker compounds appeared to be cleared from the body in OS-EL slower than OS-E as evidenced by their smaller mean clearance values (table 3). In addition, marker compounds in OS-E showed longer half-life compared to OS-EL. This result may imply that the marker compound which was more distributed into the tissue retained in blood compartment for a longer time (table 3).

Pharmacokinetic results of marker compounds after oral administration of OS-E and OS-EL are presented in table 4. An increase of the plasma concentration of RA, TMF, SIN and EUP was 
observed after oral administration of the OS-E and OS-EL which may indicate absorption of these standard compounds into the blood. The standard compounds in OS-E showed relatively lower $\mathrm{C}_{\max }$ and $\mathrm{T}_{\max }$ compared to OS-EL. These results indicate that standard compounds in OS-E extract stayed in the body for relatively shorter time compared to OS-EL. The AUC values of OS-EL were extremely larger than OS-E after oral administration, which indicates a great absorption and utility of the standard compounds in rat plasma. Similarly, oral bioavailability of marker compounds in OS-EL was higher than OS-E (table 4).
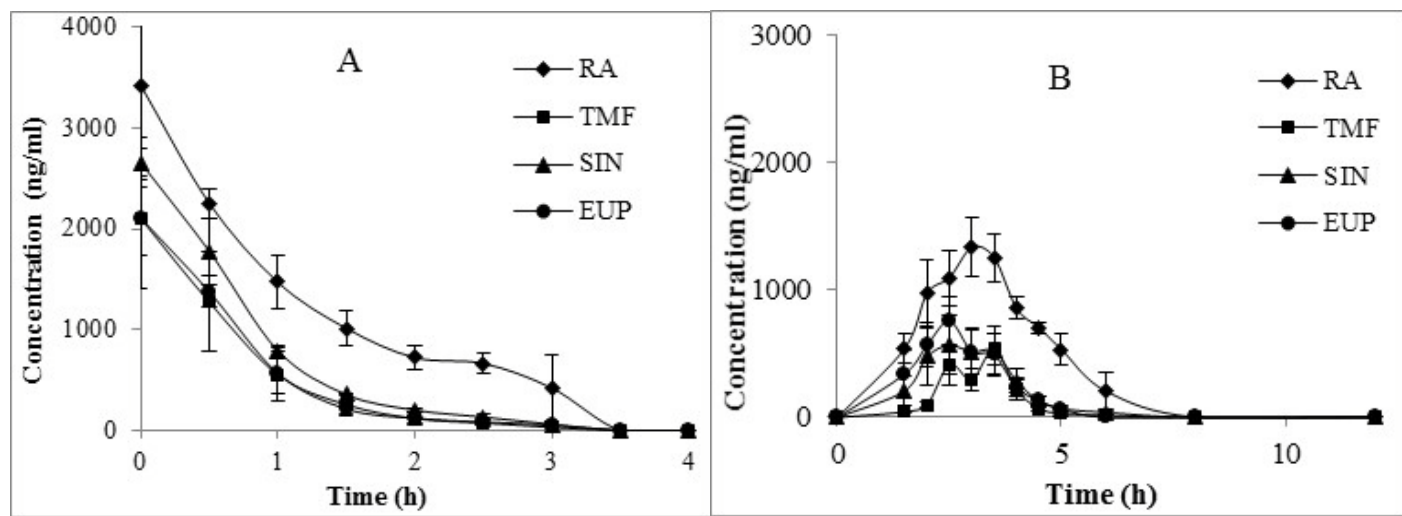

Fig. 6: Mean plasma concentration-time profiles (mean \pm SEM, $n=6)$ of $R A, T M F$, SIN and EUP after intravenous at $250 \mathrm{mg} / \mathrm{kg}(\mathrm{A})$ and oral at $1000 \mathrm{mg} / \mathrm{kg}$ (B) administration of OS-E
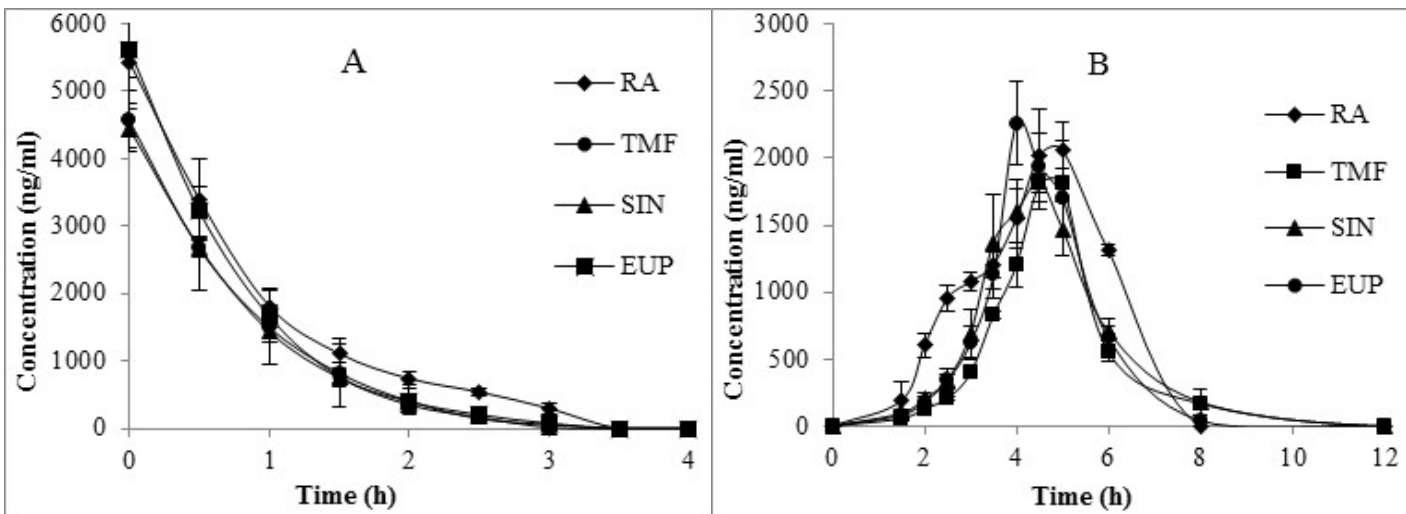

Fig. 7: Mean plasma concentration-time profiles (mean \pm SEM, $\mathrm{n}=6$ ) of $\mathrm{RA}, \mathrm{TMF}, \mathrm{SIN}$ and EUP after intravenous at $250 \mathrm{mg} / \mathrm{kg}(\mathrm{A})$ and oral at $500 \mathrm{mg} / \mathrm{kg}(\mathrm{B})$ administration of OS-EL

Table 3: Pharmacokinetic parameters of RA, TMF, SIN and EUP in rat plasma after intravenous administration of OS-E and OS-EL (n=6)

\begin{tabular}{|c|c|c|c|c|c|c|c|c|c|}
\hline \multirow[t]{2}{*}{ Data } & \multirow[t]{2}{*}{ Unit } & \multicolumn{4}{|l|}{ OS-E } & \multicolumn{4}{|l|}{ OS-EL } \\
\hline & & RA & TMF & SIN & EUP & RA & TMF & SIN & EUP \\
\hline $\operatorname{AUC}_{(24-\infty)}$ & $\mu \mathrm{g} \mathrm{h} / \mathrm{ml}$ & $4.13 \pm 0.15$ & $1.68 \pm 0.27$ & $2.32 \pm 0.10$ & $1.73 \pm 0.02$ & $5.30 \pm 0.26^{*}$ & $3.93 \pm 0.37^{*}$ & $3.81 \pm 0.09^{*}$ & $4.56 \pm 0.10^{*}$ \\
\hline $\mathrm{Ke}$ & $\mathrm{h}^{-1}$ & $0.62 \pm 0.03$ & $1.44 \pm 0.06$ & $1.30 \pm 0.05$ & $1.30 \pm 0.03$ & $0.95 \pm 0.02^{*}$ & $1.45 \pm 0.01$ & $1.46 \pm 0.10$ & $1.43 \pm 0.06$ \\
\hline$t_{1 / 2}$ & $\mathrm{~h}$ & $1.13 \pm 0.06$ & $0.49 \pm 0.02$ & $0.54 \pm 0.02$ & $0.53 \pm 0.01$ & $0.73 \pm 0.02^{*}$ & $0.48 \pm 0.01$ & $0.49 \pm 0.03$ & $0.49 \pm 0.02$ \\
\hline$V_{\mathrm{d}}$ & $\mathrm{l} / \mathrm{kg} \mathrm{h}$ & $1.06 \pm 0.08$ & $0.09 \pm 0.01$ & $0.14 \pm 0.00$ & $0.09 \pm 0.00$ & $0.55 \pm 0.04^{*}$ & $0.03 \pm 0.00^{*}$ & $0.08 \pm 0.00^{*}$ & $0.03 \pm 0.00^{*}$ \\
\hline$C L$ & $\mathrm{l} / \mathrm{kg} \mathrm{h}$ & $0.66 \pm 0.04$ & $0.12 \pm 0.01$ & $0.19 \pm 0.01$ & $0.12 \pm 0.00$ & $0.52 \pm 0.03^{*}$ & $0.05 \pm 0.00^{*}$ & $0.12 \pm 0.00$ & $0.05 \pm 0.00^{*}$ \\
\hline
\end{tabular}

$*(P \leq 0.05)$ significantly different compared with OS-E extract.

Table 4: Pharmacokinetic parameters of RA, TMF, SIN and EUP in rat plasma after oral administration of OS-E and OS-EL (n=6)

\begin{tabular}{|c|c|c|c|c|c|c|c|c|c|}
\hline \multirow[t]{2}{*}{ Data } & \multirow[t]{2}{*}{ Unit } & \multicolumn{4}{|l|}{ OS-E } & \multicolumn{4}{|l|}{ OS-EL } \\
\hline & & RA & TMF & SIN & EUP & RA & TMF & SIN & EUP \\
\hline $\operatorname{AUC}_{(0-24)}$ & $\mu \mathrm{g} \mathrm{h} / \mathrm{ml}$ & $4.37 \pm 0.28$ & $0.91 \pm 0.06$ & $1.57 \pm 0.30$ & $1.74 \pm 0.26$ & $7.41 \pm 0.14^{*}$ & $5.02 \pm 0.16^{*}$ & $5.80 \pm 0.17^{*}$ & $5.69 \pm 0.25^{*}$ \\
\hline $\mathrm{C}_{\max }$ & $\mu \mathrm{g} / \mathrm{ml}$ & $1.89 \pm 0.07$ & $0.77 \pm 0.05$ & $1.06 \pm 0.12$ & $1.29 \pm 0.15$ & $2.56 \pm 0.10^{*}$ & $1.96 \pm 0.06^{*}$ & $2.31 \pm 0.18^{*}$ & $2.91 \pm 0.02^{*}$ \\
\hline $\mathrm{T}_{\max }$ & $\mathrm{h}$ & $2.83 \pm 0.23$ & $3.17 \pm 0.23$ & $2.92 \pm 0.26$ & $3.08 \pm 0.33$ & $4.67 \pm 0.26^{*}$ & $4.67 \pm 0.12^{*}$ & $4.42 \pm 0.26^{*}$ & $4.42 \pm 0.22^{*}$ \\
\hline $\begin{array}{l}\text { Oral } \\
\text { bioavailability }\end{array}$ & $\%$ & $26.45 \pm 1.42$ & $15.28 \pm 2.55$ & $16.86 \pm 3.13$ & $24.95 \pm 3.49$ & $70.64 \pm 3.87^{*}$ & $66.26 \pm 5.95^{*}$ & $76.61 \pm 3.99^{*}$ & $81.39 \pm 2.46^{*}$ \\
\hline
\end{tabular}

* $(P \leq 0.05)$ significantly different compared with OS-E extract.

\section{DISCUSSION}

Medicinal plant whose therapeutic efficacy is based on combined action of a mixture of constituents. This modulates multiple targets with fewer adverse effects and lower toxicity simultaneously and offers new treatment opportunities [15]. The medicinal plant is attractive for medicinal use because of having pool chemical compounds and natural products. Therefore, increasing attention 
has been paid to the scientific evaluation of medicinal plants. Efficient detection and rapid characterization of natural products play key roles as an analytical support in the work of natural products chemists [16]. Pharmacokinetics of multi-component is feasible with semi-quantitative analysis based on peak area versus time. It also helps to reveal the potential active chemical constituents [17]

OS has been traditionally used for treating urinary lithiasis, edema, inflammation, eruptive fever, influenza, hepatitis, jaundice, biliary, rheumatism, diabetes, hypertension, diuretic, and a remedy for kidney stones [18-20]. Chemical studies showed caffeic acid derivatives (RA) and three main flavonoids (lipophilic flavones) including SIN, TMF and EUP are the major chemical constituent of OS extracts [7]. However, lipophilic compounds (TMF, SIN and EUP) suffer from poor aqueous solubility that limits the OS oral bioavailability and therapeutic applications. Therefore, in this study improvement of solubility and bioavailability of the lipophilic flavones present in the OS-E extract by liposomal drug delivery systems (OS-EL) was studied. This is the first study on the timecourse analysis of RA, TMF, SIN, and EUP concentration after oral and IV administration of OS-E and OS-EL extracts in rat's plasma.

OS-EL showed lower $V_{d}$, half-life $\left(t_{1 / 2}\right)$ and $C L$, higher peak concentration and larger AUC values for all standard compounds compared to OS-E after IV administration. This indicates that in OSE, standard compounds are able to distribute into the tissue compartment and remain in blood plasma relatively more than OSEL. However, in OS-EL, standard compounds appeared to be cleared from the body slower than OS-E as evidenced by their smaller mean clearance values. Moreover, the concentration of the marker compounds in OS-EL was higher than OS-E. These results revealed good improvement in aqueous solubility and bioavailability of marker compounds in OS-EL compared to OS-E extracts.

Oral administration of OS-EL indicated the slow rise of marker compounds. This was followed by a gradual decline to 0 after $12 \mathrm{~h}$. However, results obtained from oral administration of OS-E showed a faster rise of marker compounds in comparison to OS-EL. The mean values of $C_{\max }$ for all marker compounds were significantly less than OS-EL $(P \leq 0.05)$ (table 4$)$.

A maximum plasma concentration of marker compounds was observed between 2.83 to $3.17 \mathrm{~h}$ and 4.42 to $4.67 \mathrm{~h}$ for OS-E and OS$\mathrm{EL}$, respectively after oral administration. In OS-E, the dissolved marker compounds could penetrate the gastrointestinal tract more easily achieving their peak plasma concentration after $2.83 \mathrm{~h}$. However, their absorption after oral administration was incomplete as evidenced by a much smaller AUC, being almost 2 times lower than OS-EL despite their oral doses of 2 times higher. The calculated absolute bioavailability values for all marker compounds in OS-E showed lower oral bioavailability compared to OS-EL (table 4). The lower oral bioavailability of marker compounds in OS-E might be contributed to their poor aqueous solubility causing only a small fraction available in dissolved form for absorption after oral administration. On the other hand, the higher oral bioavailability of marker compounds in OS-EL can be explained due to encapsulation in phospholipids, increased solubility, and the presence of nano scale liposomes, increased negativity and colloidal stability [21]. Previous research on anionic liposomes has shown enhancement of colloidal stability and absorption [22], and even with higher cellular uptake than neutral and cationic liposomes [23-24].

\section{CONCLUSION}

A simple and sensitive HPLC-UV detection method was developed for the simultaneous plasma determination of four marker compounds (RA, TMF, SIN and EUP) from OS extracts. This method is precise for the quantitative analysis of selected marker compounds. Additional advantages over other known methods include simple preparation of the sample, as well as low detection and quantification limits. The method was successfully applied in the pharmacokinetics study of the OS-E and OS-EL on rats. Intravenous administration revealed that all four marker compounds in OS-EL appeared to be poorly distributed. The markers cleared slowly from the body compared to OS-E. However, the marker compounds were absorbed rapidly in OS-E, following oral administration. Their absorption was incomplete with calculated absolute oral bioavailability values as indicated in table 4 . Bioavailability of all marker compounds was higher in OS-EL oral than OS-E, due to the higher solubility of encapsulation in phospholipids.

\section{ACKNOWLEDGEMENT}

The authors would like to acknowledge Universiti Sains Malaysia for the financial support given under the USM Fellowship Scheme. This project was funded by the Malaysian Ministry of Agriculture and Agro-Based Industry, NKEA Research Grant Scheme (NRGS), Ref. No.: 304/PFRMASI/650738/K123.

\section{CONFLICTS OF INTERESTS}

All authors have no conflicts of interests to declare.

\section{REFERENCES}

1. Ahamed MBK, Aisha AF, Nassar ZD, Siddiqui JM, Ismail Z, Omari $\mathrm{S}$, et al. Cat's whiskers tea (Orthosiphon stamineus) extract inhibits the growth of colon tumour in nude mice and angiogenesis in endothelial cells via suppressing VEGFR phosphorylation. Nutr Cancer 2012;64:89-99.

2. Sumaryono W, Proksch P, Wray V, Witte L, Hartmann T. Qualitative and quantitative analysis of the phenolic constituents from orthosiphon aristatus. Planta Med 1991;57:176-80.

3. Olah NK, Radu L, Mogoşan C, Hanganu D, Gocan S. Phytochemical and pharmacological studies on Orthosiphon stamineus Benth. (Lamiaceae) hydroalcoholic extracts. J Pharm Biomed Anal 2003;33:117-23.

4. Arafat OM, Tham SY, Sadikun A, Zhari I, Haughton PJ, Asmawi MZ. Studies on diuretic and hypouricemic effects of Orthosiphon stamineus methanol extracts in rats. J Ethnopharmacol 2008;118:354-60.

5. Akowuah GA, Zhari I, Norhayati I, Sadikun A, Khamsah SM. Sinensetin, eupatorin, ' 3 -hydroxy-5, 6,' 7, 4 tetramethoxyflavone and rosmarinic acid contents and antioxidative effect of Orthosiphon stamineus from Malaysia. Food Chem 2004;87:559-66.

6. Siddiqui MJA, Ismail Z. Simultaneous analysis of bioactive markers from orthosiphon stamineus benth leaves extracts by reverse phase high-performance liquid chromatography. Trop J Pharm Res 2011;10:97-103.

7. Abdalrahim FAA, Amin Malik SAM, Zhari I. Preparation and characterization of nanoliposomes of Orthosiphon stamineus ethanolic extract in soybean phospholipids. BMC Biotechnol 2014;14:1-11.

8. Zhang A, Sun H, Wang X, Jiao G, Yuan Y, Sun W. Simultaneous in vivo RP-HPLC-DAD quantification of multiple-component and drug-drug interaction by pharmacokinetics, using 6, 7-dimethylesculetin, geniposide and rhein as examples. Biomed Chromatogr 2012;26:844-50.

9. Wang $\mathrm{X}$, Sun $\mathrm{H}$, Zhang A, Jiao G, Sun W, Yuan Y. Pharmacokinetics screening for multi-components absorbed in the rat plasma after oral administration traditional Chinese medicine formula yin-chen-hao-tang by ultra-performance liquid chromatography-electrospray ionisation/quadrupoletime-of-flight mass spectrometry combined with pattern recognition methods. Analyst 2011;136:5068-76.

10. Murugaiyah V, Chan KL. Analysis of lignans from Phyllanthus niruri L. in plasma using a simple HPLC method with fluorescence detection and its application in a pharmacokinetic study. J Chromatogr B 2007;852:138-44.

11. Sun H, Yin Q, Zhang A, Wang X. UPLC-MS/MS performing pharmacokinetic and biodistribution studies of rhein. J Sep Sci 2012;35:2063-8.

12. Pietta P, Mauri P, Gardana C, Bruno A. High-performance liquid chromatography with diode-array ultraviolet detection of methoxylated flavones in Orthosiphon leaves. J Chromatogr A 1991;547:439-42.

13. Mouly P, Gaydou EM, Auffray A. Simultaneous separation of flavanone glycosides and polyethoxylated flavones in citrus juices using liquid chromatography. J Chromatogr A 1998;800:171-9. 
14. International Conference on Harmonisation of Technical Requirements for Registration of Pharmaceuticals for Human Use (ICH). Q2B Validation of Analytical Procedures: Methodology. Department of Health and Human Services Food and Drug Administration, U. S; 1996.

15. Wang $X$, Sun H, Zhang A, Sun W, Wang $P$, Wang Z. The potential role of metabolomics approaches in the area of traditional Chinese medicine: as pillars of the bridge between Chinese and Western medicine. J Pharm Biomed Anal 2011;55:859-68.

16. Sun H, Dong W, Zhang A, Wang W, Wang X Pharmacokinetics study of multiple components absorbed in rat plasma after oral administration of Stemonae radix using ultra-performance liquid chromatography/mass spectrometry with automated MetaboLynx software analysis. J Sep Sci 2012;35:3477-85.

17. Yin Q, Sun H, Zhang A, Wang X. Pharmacokinetics and tissue distribution study of scoparone in rats by ultra performance liquid chromatography with tandem high-definition mass spectrometry. Fitoterapia 2012;83:795-800.

18. Dat DD, Ham NN, Khac DH, Lam NT, Son PT, Dau NV, et al. Studies on the individual and combined diuretic effects of four Vietnamese traditional herbal remedies (Zea mays, Imperata cylindrica, Plantago major and Orthosiphon stamineus). J Ethnopharmacol 1992;36:225-31.
19. Tezuka Y, Stampoulis P, Banskota AH, Awale S, Tran KQ, Saiki I, et al. Constituents of the vietnamese medicinal plant orthosiphon stamineus. Chem Pharm Bull 2000;48:1711-9.

20. Awale S, Tezuka Y, Banskota AH, Kouda K, Tun KM, Kadota S. Five novel highly oxygenated diterpenes of orthosiphon stamineus from Myanmar. J Nat Prod 2001;64:592-6.

21. Guan S, Qin X, Zhou Z, Zhang Q, Huang Y. Investigation of the mechanisms of improved oral bioavailability of bergenin using bergenin-phospholipid complex. Drug Dev Ind Pharm 2013;40:163-71.

22. Gülseren I, Guri A, Corredig M. Encapsulation of Tea polyphenols in nanoliposomes prepared with milk phosphorlipids and their effect on the viability of HT-29 human carcinoma cells. Food Digestion 2012;3:36-45.

23. Bajoria R, Sooranna SR, Contractor SF. Endocytotic uptake of small unilamellar liposomes by human trophoblast cells in culture. Hum Reprod 1997;12:1343-8.

24. Ogiso T, Yamaguchi T, Iwaki M, Tanino T, Miyake Y. Effect of positively and negatively charged liposomes on skin permeation of drugs. J Drug Target 2001;9:49-59.

\section{How to cite this article}

- $\quad$ Armaghan Shafaei, Mohammed Ali Ahmed Saeed, Abdalrahim FA Aisha, Zhari Ismail. Pharmacokinetics and bioavailability of Orthosiphon stamineus ethanolic extract and ITS nano Liposomes in Sprague dawley rats. Int J Pharm Pharm Sci 2017;9(1):199-206. 